\title{
Dengue vector control and surveillance during a major outbreak in a coastal Red Sea area in Sudan
}

O.M.E. Seidahmed, ${ }^{1}$ H.A.M. Siam, ${ }^{7}$ M.A. Soghaier, ${ }^{2}$ M. Abubakr, ${ }^{3}$ H.A. Osman, ${ }^{4}$ L.S. Abd Elrhman, ${ }^{4}$ B. Elmagbol ${ }^{2}$ and R. Velayudhan ${ }^{5}$

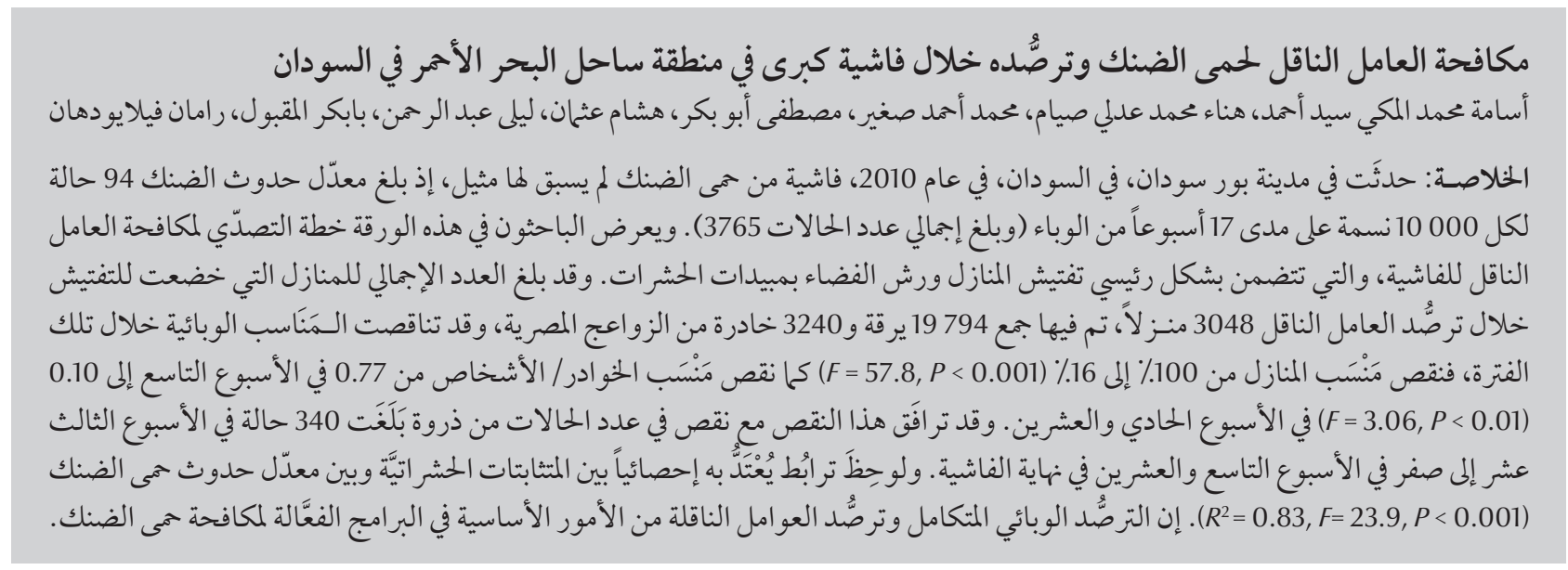

ABSTRACT An unprecedented dengue outbreak occurred in 2010 in Port Sudan city, Sudan. Dengue incidence was 94 cases per 10000 observed over 17 epidemiological weeks (total cases $=3765$ ). We report here the impact of the vector control response plan to the outbreak, which mainly entailed house inspection and insecticide space spraying. In total 3048 houses were inspected during vector surveillance and 19794 larvae and 3240 pupae of Aedes aegypti were collected. Entomological indices decreased during the period: house index declined from $100 \%$ to $16 \%(F=57.8, P<0.001)$ and pupal/person $(\mathrm{P} / \mathrm{P})$ index from 0.77 to $0.10(F=3.06$, $P<0.01)$ in weeks 9 and 21 respectively. This decline was accompanied by a decrease in cases from a peak of 341 cases in week 13 to zero in week 29 and the end of the outbreak. There was a significant correlation between the entomological parameters and dengue incidence $\left(R^{2}=0.83, F=23.9, P<0.001\right)$. Integrated epidemiological and vector surveillance is essential to an effective dengue control programme

\section{Surveillance du vecteur de la dengue et actions de lutte pendant une importante flambée dans une zone côtière de la Mer rouge au Soudan}

RÉSUMÉ Une flambée de dengue sans précédent s'est produite en 2010 dans la ville de Port Soudan (Soudan). L'incidence de la dengue était de 94 cas pour 10000 observés pendant 17 semaines épidémiologiques (nombre total de cas = 3 765). Nous présentons ici l'impact du plan de riposte visant à lutter contre le vecteur de la flambée. Ce plan consistait principalement en l'inspection des logements et la pulvérisation d'insecticides. Au total, 3048 logements ont été inspectés pendant la surveillance du vecteur et 19794 larves et 3240 nymphes d'Aedes aegypti ont été recueillies. Les indices entomologiques ont diminué pendant la période : l'indice « habitations » est passé de $100 \%$ à $16 \%(F=57,8 ; P<0,001)$ et l'indice nymphe/personne est passé de 0,77 à $0,10(F=3,06 ; P$ $<0,01)$ au cours des semaines 9 et 21 respectivement. Cette diminution a été accompagnée par une diminution du nombre de cas, passant d'un pic de 341 cas en semaine 13 à zéro en semaine 29 et à la fin de la flambée. Une corrélation significative a été retrouvée entre les paramètres entomologiques et l'incidence de la dengue $\left(R^{2}=\right.$ $0,83 ; F=23,9 ; P<0,001)$. Une surveillance vectorielle et épidémiologique intégrée est essentielle pour garantir l'efficacité d'un programme de lutte contre la dengue.

'Department of Medical Entomology, National Health Laboratory, Ministry of Health, Khartoum, Sudan (Correspondence to O.M.E. Seidahmed: osamamekki@gmail.com).2National Control Programme of Epidemics and Zoonotic Diseases, Ministry of Health, Khartoum, Sudan. ${ }^{3}$ Department of Environmental Health, Ministry of Health, Khartoum, Sudan. ${ }^{4}$ Ministry of Health of Red Sea State, Port Sudan, Sudan. ${ }^{5}$ Department of Control of Neglected Tropical Diseases, World Health Organization, Geneva, Switzerland.

Received: 19/06/11; accepted: 11/01/12 


\section{Introduction}

Dengue is the most important arthropod-borne viral infection of humans. Worldwide, an estimated 2.5 billion people are at risk of infection, approximately 1 billion live in urban areas in tropical and sub-tropical countries in South-East Asia, the Western Pacific and the American regions of the World Health Organization (WHO) [1]. In the WHO Eastern Mediterranean Region, dengue is an emerging health problem in several countries such as Djibouti, Pakistan, Saudi Arabia, Somalia, Sudan and Yemen $[2,3]$.

The coastal area of the Red Sea state of Sudan has been subject to repetitive outbreaks of dengue fever (DF) and dengue haemorrhagic fever (DHF) in the past decade, particularly the main port of the country, Port Sudan (19 $37^{\prime}$ $\mathrm{N} ; 37^{\circ} 13^{\prime}$ E) [4] National programme for Epidemics Control and Zoonotic Diseases, Sudan, unpublished data, 2010]. Three serotypes of the virus (DENV1, DENV2 and DEN3) are known to circulate $[5,6]$, and infestations of Aedes aegypti, the mosquito vector, have been documented in the area [3]; this is linked to the limited drinking-water and consequent water storage habits of the local community [7]. A lack of an efficient surveillance system has resulted in delayed response to these outbreaks. Moreover, the vector control approach during these outbreaks was the same as that for a malaria outbreak. Interventions were been selected and implemented without consideration to differences in bionomics and ecology between the malaria and dengue vectors [OME Seidahmed, unpublished report, 2010].

An unprecedented dengue outbreak started in January 2010 in Port Sudan [3]. In this report, we describe how vector control and surveillance were promoted and incorporated in the response plan to the outbreak, and the operational outcomes in terms of evaluation of vector control interventions and the monitoring of the course of the outbreak.

\section{Methods}

\section{Selection of vector control interventions}

Selection of vector control interventions was based on findings of research work carried out in 2008-2009 [3]. In addition, a preliminary survey was carried out at the beginning of the outbreak in March 2010. The survey aimed to:

- explore whether another dengue vector species other than Aedes aegypti had infested the outbreak area, particularly where cases of DHF were reported;

- determine key breeding containers (i.e. highly productive containers with $>80 \%$ of all adult mosquitoes with the dengue vector, as determined by pupal counts);

- assess productivity of the key container(s) in relation to location (indoor or outdoor);

- explore pre-intervention entomological indices, mainly house index (HI) and pupal/person $(\mathrm{P} / \mathrm{P})$ index;

- check biting time(s) and resting site(s) of the dengue vector.

\section{Vector surveillance}

Sentinel sites \& vector surveillance team

Eight sentinel sites were defined and fixed in Port Sudan city; these covered the 3 administrative division of the city: eastern (Abuhasheish, Elthora and Elgadisia), middle (downtown and Wihda) and southern sectors (Transeet, Elmatar and Darelnaeem).

Eight health workers were trained on basic water filtration and mosquito collection using water sieves, hose pipes, white-enamel trays and pipettes from typical containers (clay-pots and barrels). In addition, sweep nets were used in water filtration from large containers such as underground tanks. The training also focused on identification of key water productive containers inside houses, and counting, sorting and transfer of pupae and larvae of Aedes mosquito to a field laboratory in Port Sudan.

\section{Surveys}

We followed the methodology of pupal demographic surveys described by Focks and others [8]. Weekly, a total of 240 houses were randomly selected and inspected for the presence of aquatic stages of Aedes, i.e. 30 houses per sentinel site.

Data collection forms were reviewed by a field entomologist, packed and emailed to the Department of Medical Entomology at the National Health Laboratory in Khartoum.

\section{Reporting}

Weekly reports on density parameters of Aedes aegypti in relation to the human population density were produced by the senior entomologist. The entomological indices included:

- $\mathrm{HI}=$ percentage of houses or premises positive for Aedes aquatic stages

- Container index $(\mathrm{CI})=$ percentage of water containers positive for Aedes aquatic stages

- Breteau index $(\mathrm{BI})=$ number of positive containers per 100 houses in a specific location

- $\mathrm{P} / \mathrm{P}$ index $=$ total number of collected pupae/total number of inhabitants in the inspected houses.

\section{Evaluation}

The interventions were regularly evaluated and verified using both weekly reports of the vector surveillance as well as spot checks of entomological surveys and supervisory visit.

\section{Results}

\section{Climatic conditions}

Meteorological data of Port Sudan was obtained from Climate Prediction Centre, National Oceanic and Atmospheric Administration. No differences 
in monthly rainfall or relative humidity were shown between the outbreak period in 2010 and the same months over the 10 previous years (2000-2009) (data not shown here). However, mean minimum temperatures during January-August 2010 were markedly higher compared to the same monthly period reported in the 10 previous years (data not shown here).

\section{Disease incidence}

Dengue infections were detected using rapid dengue $\operatorname{IgM} / \operatorname{IgG}$ tests, and NS1 ELISA and IgM ELISA assays. Furthermore, a subsample was sent to the National Health Laboratory for real-time polymerase chain reaction (RT-PCR) analysis. The analysis confirmed that DEN-3 was the circulating virus strain (data not shown here).

A total of 3765 DF/DHF cases were reported in Port Sudan over $17 \mathrm{ep}$ idemiological weeks (27 February-25 June 2010. The total population at risk was 400000 . Hence, the incidence rate during this outbreak was 94 cases per 10000 .

Interestingly, dengue incidence was higher in the eastern and southern sectors (odds ratios $=2.44$ and 2.07 respectively) compared to the middle sector (odds ratio $=1.88$ ). However, the difference was only significant between the middle and eastern sectors $(P<0.05)$. Conversely, entomological indices (HI, CI, BI, P/P) were higher in the middle sector compared to the other 2 sectors. The difference was also significant between the middle and eastern sectors $(P<0.05)$ (Table 1$)$.

\section{Vector control interventions and evaluation}

As a result of the preliminary survey, an array of vector control interventions was selected to work effectively against the dengue vector Aedes aegypti, which is NOT a malaria vector (Box 1 ). The vector control interventions adopted were in accordance with WHO guidelines [1]; these entailed:

- community mobilization (scrubbing and drying of unused containers by householders);

- active source reduction by health workers, particularly where DF/ DHF were reported;

- focal space spraying of affected districts using a knock-down insecticide;

- larviciding of outdoor productive containers;

- distribution of long-lasting insecticide treated nets (LLINs) to the inand outpatients.

The entire set of interventions was implemented in areas where clusters of cases were reported (transmission foci).

Coverage rates of the interventions adopted during the March-May period are presented in Table 2. The results of the evaluation work of vector control are presented in Box 2 .

\section{Vector surveillance}

A total of 3048 houses were inspected during the vector surveillance work. Vector surveys over 14 weeks resulted in collection of 19794 larvae and 3240 pupae of Aedes aegypti. Different categories of water storage containers were found in the houses. These ranged in size from small containers (<100 L) such as jerkins to medium size (150-250 L) such as clay-pots and plastic barrels to large size (> 250 L) such as ground and underground tanks. A total of 11524 indoor water storage containers were examined, 2536 of which were found to be infested with larvae and/or pupae of Aedes aegypti (Table 3). Among all storage water containers, the key vessels containing pupae of the dengue vector were clay pots (75\%) and plastic barrels (15\%).

A significant decrease in the entomological indices was found during the observed period (Figure 1). HI declined from $100 \%$ to $16 \%(F=57.8, P<0.001)$, while the $\mathrm{P} / \mathrm{P}$ index decreased from 0.77 to $0.10(F=3.06, P<0.01)$ from the 9 th to the 21st week. Accordingly, this decline was accompanied by a cessation in dengue transmission from 9 cases per 10000 in the 13th week (341 new cases) to zero incidence in the 29th week.

Using regression analysis, a significant relationship was found between the entomological parameters and dengue incidence over the weeks of surveillance $\left(R^{2}=0.83, F=23.9, P<0.001\right)$.

\begin{tabular}{|c|c|c|c|}
\hline \multirow[t]{2}{*}{ Measure } & \multicolumn{3}{|c|}{ Administrative sector } \\
\hline & Eastern & Southern & Middle \\
\hline Number of cases & 1272 & 1291 & 1202 \\
\hline Cases OR $(95 \% \mathrm{Cl})$ & $2.40^{\mathrm{a}}(2.21-2.61)$ & $2.07^{\mathrm{a}, \mathrm{b}}(1.90-2.25)$ & $1.88^{\mathrm{b}}(1.73-2.05)$ \\
\hline House index $(95 \% \mathrm{Cl})$ & $35.9 \%^{\mathrm{a}}(31-38.9)$ & $39.4 \%$ a,b $(38.5-40.6)$ & $41.1 \%$ b $(37.9-44.7)$ \\
\hline Container index $(95 \% \mathrm{Cl})$ & $18.4 \%^{\mathrm{a}}(16.3-20.4)$ & $20.9 \%{ }^{a, b}(18.1-24.3)$ & $26.7 \%^{\mathrm{b}}(24-29.3)$ \\
\hline Breteau index (95\% Cl) & $55.1^{\mathrm{a}}(49-61.1)$ & $62.8^{\mathrm{a}, \mathrm{b}}(54.1-72.7)$ & $80.1^{\mathrm{b}}(71.9-87.9)$ \\
\hline Pupal/person (95\% Cl) & $0.19^{\mathrm{a}}(0.15-0.23)$ & $0.22^{a, b}(0.18-0.26)$ & $0.31^{\mathrm{b}}(0.24-0.46)$ \\
\hline
\end{tabular}

${ }^{a, b}$ Significant differences within the same row using Kruskal-Wallis test.

$O R=$ odds ratio; $\mathrm{Cl}=$ confidence interval. 


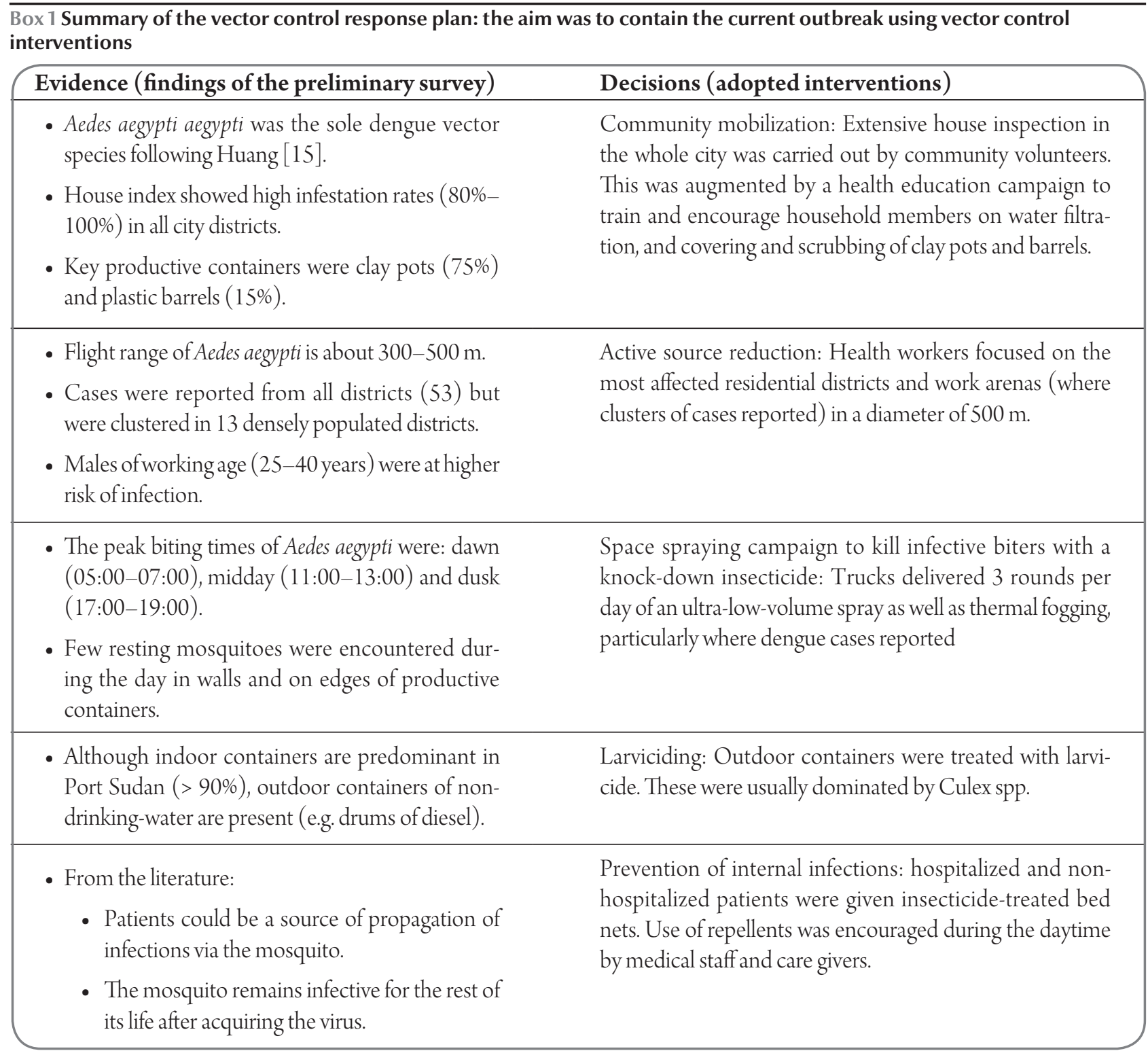

\section{Discussion}

The response to dengue outbreaks involves developing and implementing action plans that aim to break the transmission cycle of the disease. In the absence of a vaccine or drugs, vector control - including personal protective measures - is the only effective strategy to prevent and control dengue transmission [9]. At the same time, vector surveillance is an integral component in the response plan; its operational purposes entail monitoring the course of the outbreak in close coordination with epidemiological surveillance, as well as evaluating control efforts.
In this work, we showed vector control was a successful factor in the containment of the 2010 outbreak. Consequently, entomological indices were reduced. Concomitantly, a decrease in dengue cases followed and eventual cessation of the outbreak was achieved. There was a significant correlation between the entomological parameters and dengue incidence.

We think among the factors that were beyond the 2010 outbreak in Port Sudan were: i) a higher mosquito production density due to higher minimum temperatures particularly during January-March 2010 and ii) a lower immunity in the population to the DEN-3 virus strain. In the past, DEN-1 and DEN-2 were the only dengue strains that circulated in Port Sudan [4]. DEN3 strain was detected in 2004 when an outbreak among children occurred [5].

A recent study on dengue epidemiology in Port Sudan showed that transmission is linked to the shortage and storage of drinking water. The city is subject to 2 transmission peaks: a winter peak and another major one during summer [3]. Most of the dengue outbreaks in Port Sudan occurred during summer peak (Ministry of Health, personal communication).

The incidence of dengue in the middle districts was lower than in the 


\begin{tabular}{|c|c|c|c|c|c|}
\hline \multirow{3}{*}{$\begin{array}{l}\text { Epidemiological } \\
\text { week }\end{array}$} & \multicolumn{2}{|c|}{ Source reduction } & \multirow{3}{*}{$\begin{array}{l}\text { Thermal fogging } \\
\text { No. houses (\% } \\
\text { coverage) }\end{array}$} & \multirow{3}{*}{$\begin{array}{l}\text { ULV space } \\
\text { spraying } \\
\text { Area in } \mathrm{km}^{\mathrm{b}} \text { (\% } \\
\text { coverage) }\end{array}$} & \multirow{3}{*}{$\begin{array}{l}\text { Larviciding of outdoor } \\
\text { breeding containers }\end{array}$} \\
\hline & By volunteers $^{c}$ & By health workers & & & \\
\hline & $\begin{array}{l}\text { No. houses } \\
\text { inspected) (\% } \\
\text { coverage) }\end{array}$ & $\begin{array}{l}\text { No. houses } \\
\text { inspected (\% } \\
\text { coverage) }\end{array}$ & & & \\
\hline 10 (6-12 Mar) & \multirow{2}{*}{$41665(72.4 \%)$} & - & $6400(7.0)$ & - & $98228(109 \%)^{d}$ \\
\hline 11 (13-19 Mar) & & $13945(24.2)$ & $9872(10.0)$ & - & $92377(102 \%)^{d}$ \\
\hline 12 (20-26 Mar) & \multirow{10}{*}{$33722^{\mathrm{e}}(58.6 \%)$} & 12454 (21.6) & $9421(10.0)$ & - & $74286(82 \%)$ \\
\hline 13 (27 Mar-2 Apr) & & $9513(16.5)$ & $5348(5.0)$ & $1050(85.0)$ & \\
\hline 14 (3-9 Apr) & & $8492(14.8)$ & $6264(6.0)$ & - & \\
\hline 15 (10-16 Apr) & & 10646 (18.5) & $5718(6.2)$ & $510(41.0)$ & \\
\hline 16 (17-23 Apr) & & $4000(7.0)$ & 3467 (3.8) & - & \\
\hline 17 (24-30 Apr) & & $7000(12.2)$ & $5558(6.0)$ & $120(9.7)$ & \\
\hline 18 (1-7 May) & & 8000 (13.9) & $11434(12.0)$ & - & \\
\hline 19 (8-14 May) & & $27113(47.1)$ & $13255(14.0)$ & - & \\
\hline 20 (15-21 May) & & 30077 (52.3) & 13622 (14.9) & - & \\
\hline 21 (22-28 May) & & 28429 (49.4) & $14000(15.5)$ & - & \\
\hline
\end{tabular}

${ }^{a}$ Only applied in areas where cases were reported; then houses within a diameter of $300 \mathrm{~m}$ were fogged.

${ }^{b}$ Applied in lanes of districts between houses in the whole city.

'Source reduction by volunteers was evaluated every 2 weeks.

${ }^{d}$ Coverage rate surpassed the targeted number.

${ }^{e} 73$ targeted districts with clusters of reported cases (> 85\% of total cases).

eastern and southern ones. Conversely, higher entomological indices (except $\mathrm{HI}$ ) were seen in the middle sector. There is a better water supply network in the middle sector; hence, residents of the middle sector do not usually store drinking water and this is shown by lower infestation rate (HI). However, more productive breeding containers were seen in this sector. One possible explanation for this discrepancy is that less infective biters existed in the middle sector compared to the other sectors.

There were some deficiencies in the case reporting system. These included misdiagnosis of early-onset cases and imprecise data on location of cases. To address this, the case reporting system was improved, rapid dengue $\operatorname{IgM} / \operatorname{IgG}$ tests were distributed and a workshop on management of dengue cases was conducted.

Nevertheless, these problems had resulted in a delayed vector control response. If the first cases are quickly and accurately diagnosed and reported then vector control can be implemented in a timely way to prevent the spread of dengue. Despite the delayed response, the epidemiological situation in Port Sudan city dramatically improved as a result of the vector control efforts.

The vector response plan was successful because it was formulated on sound scientific evidence. This included information on the eco-epidemiology of the disease in the area as well as international experience on dengue control. However, the plan was stopped after 14 weeks for budget constraints; fortunately, this happened after the transmission cycle was interrupted. However, the cessation of the plan could have had a negative impact if it had occurred before interruption of the transmission cycle. Adverse outcomes of such a scenario might include resurgence in vector density and then incidence of DF/DHF among vulnerable groups.

Community mobilization was an integral part of the response plan.
Immediate efforts were directed to source reduction carried out by volunteers. Although, the coverage rate was $>70 \%$, no significant decrease in entomological indices was shown between pre- and post-campaigns. One of the challenges to community mobilization is compliance of household members to regularly scrub and filter their drinking containers. This requires a continuous health education programme to promote community participation. Community mobilization was successful in Vietnam but only after 9 years of intensive work. There, the programme focused on biological control combined with promoting better water management practices. These efforts have resulted in the elimination of the dengue vector in northern and central Vietnam [10].

Active source reduction by the health workers was also instigated and considerably contributed to dengue control in the targeted areas 


\section{Intervention}

tion + House

inspection

campaign by

community vol-

unteers $(\mathrm{HE}+)$

House inspec-

tion by health

workers

Space spraying

Larviciding

\section{Activities (how this was done and supported)}

- Four rounds of the HE+ campaign were carried out in the whole city to:

- develop recognition of aquatic stages and explain methods of source reduction ( 378 female volunteers from the Red Crescent, 120 male volunteers from community guards)

- address control of key productive containers.

- The following activities were carried out.

- Pamphlets were distributed to households (34000 in total).

- Daily radio messages were broadcast.

- Written messages and video clips were advertised on the streets.

- Lectures of HE were conducted in 28 social and sport clubs.

- Routine programme of inspection by 80 health workers was done according to a coverage timetable and in areas of reported dengue cases (Table 1).

- Rounds of space spraying were carried out (each for 7 days) (Table 1).

- Indoor and outdoor thermal fogging was carried out daily.

- Permethrin (Agniban 25\% EC) was applied in a dosage $0.11 \mathrm{mg} / \mathrm{L}$.

\section{Evaluation (what was learned)}

- Entomological surveys showed no significant impact by $\mathrm{HE}+$ (reduction rates were $1 \%-5 \%$ between pre- and post-campaigns)

- Check on community volunteers showed the following.

- Shortened message was delivered to households (drinking containers instead of water storage containers were targeted).

- Pamphlets were delivered to households without training household member (only $20 \%-30 \%$ of houses checked after the campaigns).

- About $10 \%-30 \%$ of the houses were locked during the campaign (residents at work or away).

- The radio broadcast had low audibility in the city ( $5 / 90$ persons asked $)$.

- Good performance of health workers was assured by:

- having 2 supervisors for each 15-25 health workers

- sending filtrated specimens to the national health laboratory.

- Entomological surveys showed significant reduction impact in targeted area (60\%-70\%).

- Check supervision for space spraying campaign operations showed the following.

- Many windows/doors were locked during the ultra-low-volume spraying. This was addressed using horn loudspeakers in the targeted districts.

- Maintenance problems regularly caused fogging machines to be out of order.

- Neither the efficacy of permethrin nor susceptibility of Aedes were tested before operations.

- Aedes mosquito rarely breeds outdoors in Port Sudan and Culex spp. predominate outdoor containers.
- Temephos (Abate) was applied in outdoor containers. Main outdoor containers were water drums of steam diesel engines. 


\begin{tabular}{lccccc}
\hline \multicolumn{7}{l}{$\begin{array}{l}\text { Table 3 Aedes aegypti larvae/pupae infestation rate, and pupae and larvae counts by container type } \\
\text { Container type }\end{array}$} & No. examined (\%) & $\begin{array}{c}\text { No. infested with } \\
\text { larvae/pupae (\%) }\end{array}$ & Pupae count (\%) & $\begin{array}{c}\text { Larvae count } \\
\text { (L1/L2) (\%) }\end{array}$ & $\begin{array}{c}\text { Larvae count } \\
\text { (L3/L4) (\%) }\end{array}$ \\
Clay pot & $5715(49.6)$ & $1826(72.0)$ & $2430(75.0)$ & $6622(65.0)$ & $6916(72.0)$ \\
Barrel & $4953(43.0)$ & $558(22.0)$ & $486(15.0)$ & $1509(14.8)$ & $1921(20.0)$ \\
Underground tanker & $285(2.5)$ & $70(2.8)$ & $98(3.0)$ & $1019(10.0)$ & $480(5.0)$ \\
Other & $571(5.0)$ & $82(3.2)$ & $226(7.0)$ & $1038(10.2)$ & $289(3.0)$ \\
Total & 11524 & 2536 & 3240 & 10188 & 9606 \\
\hline
\end{tabular}

(coverage rate $\geq 85 \%$ ). This method is usually followed during dengue outbreaks. Likewise, source reduction was carried out during the 1998 outbreak in Trinidad [11] and the 2005 outbreak in Singapore [12]. In the Singapore outbreak, "carpet combing" campaigns were carried out weekly. These campaigns involved recruiting more health workers, volunteers and town councils and resulted in removing 1000 breeding containers and containment of the outbreak [12]. On the other hand, vector control efforts failed to reduce mosquito densities beyond the transmission threshold in Trinidad; this was attributed to poor performance on active inspection [11].
In addition, 3 cycles of focal space spraying were carried out in selected districts in Port Sudan. In a systematic review of dengue control programmes, results showed that chemical interventions are ineffective, while educational campaigns seem to be effective. The review concluded that standardization of interventions, besides monitoring and

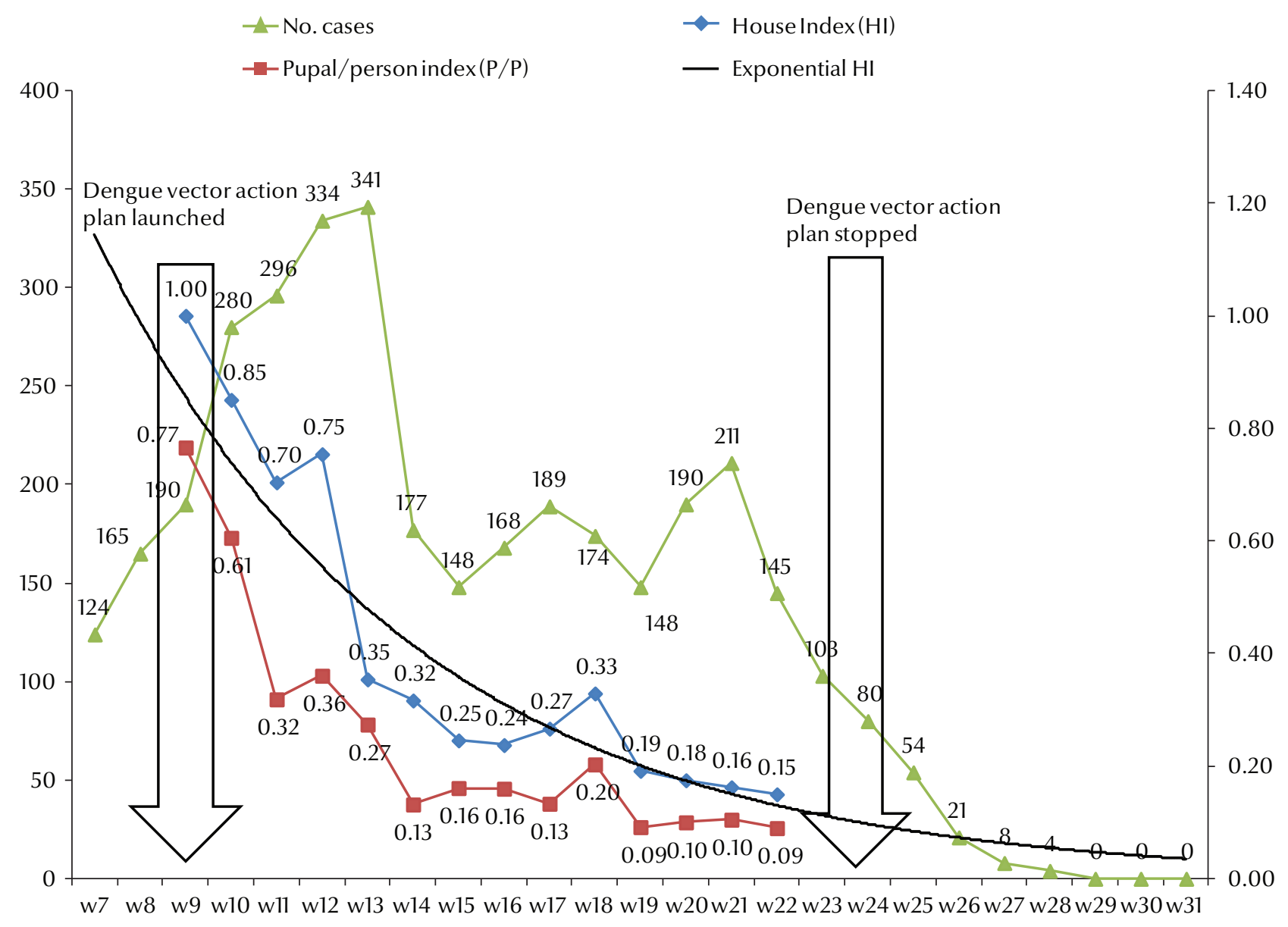

Epidemiologicalweeks

Figure 1 Trend of dengue cases in relation to vector surveillance parameters ( $\mathrm{HI}$ and $\mathrm{P} / \mathrm{P}$ ) over 25 epidemiological weeks (13/02/2010-11/06/2010) during the 2010 dengue outbreak in Port Sudan city 
evaluation, is needed [13]. However, these findings relate to non-epidemic situations. We think chemical control should be a part of response plans in the case of dengue epidemics.

In the 2010 epidemic it has been difficult to separate the effectiveness of each intervention in the containment of the outbreak as we used an integrated vector control approach. Erlanger and others reviewed the relative effectiveness of vector control interventions using entomological parameters [14]. They found integrated vector management is the most effective approach to control dengue. They suggested that vector control should use a community approach. Also, it should be tailored to the eco-epidemiological conditions of the targeted area.

During the 2010 dengue outbreak, weekly reports on the vector surveillance were generated evaluating the response plan and anticipating the situation for the upcoming weeks. The weekly report was delivered promptly to the national control programme of epidemics and state Ministry of Health.

This work clearly shows the impact of effective entomological surveillance with coordinated control intervention on dengue disease transmission. Integrated epidemiological and vector surveillance should be a cornerstone of an effective dengue control programme or integrated surveillance system for emerging arboviral diseases in Sudan.

\section{Acknowledgements}

The authors wish to thank the vector surveillance team in Port Sudan for their excellent performance. We are also grateful to the staff of federal/state Ministry of Health who worked diligently during the outbreak response activities, and to Ms Safa Hassan who participated in data entry.

\section{References}

1. Dengue: guidelines for diagnosis, treatment, prevention and control. New edition, 2009. Geneva, World Health Organization, 2009 (WHO/HTM/NTD/DEN/2009.1).

2. Spread of dengue fever: the challenges. DCD Newsletter, 2005, 6:7-8.

3. Seidahmed $\mathrm{O}$ et al. Spatial and temporal patterns of dengue transmission along a Red Sea coastline: a longitudinal entomological and serological survey in Port Sudan City. PLoS Neglected Tropical Diseases, 2012, 6(9):e1821.

4. Kay B, Vu SN. New strategy against Aedes aegypti in Vietnam. Lancet, 2005, 365:613-617.

5. Hyams KC et al. Evaluation of febrile patients in Port Sudan, Sudan: isolation of dengue virus. American Journal of Tropical Medicine and Hygiene, 1986, 35:860-865.

6. Malik A et al. Dengue hemorrhagic fever outbreak in children in Port Sudan. Journal of Infection and Public Health, 2011, 4:1-6.

7. Lewis DJ. The Aedes mosquitoes of the Sudan. Annals of Tropical Medicine and Parasitology, 1955, 49:164-173.

8. Multi-country study of Aedes aegypti pupal productivity survey methodology findings and recommendations. Geneva, World Health Organization on behalf of the Special Programme for Research and Training in Tropical Diseases, 2006 (http:// www.who.int/tdr/publications/documents/aedes_aegypti. pdf, accessed 1 November 2012).
9. Guidelines for conducting a review of a national dengue prevention and control programme. Geneva, World Health Organization, 2005 (WHO/CDS/CPE/PVC/2005.13).

10. Nam VS et al. Community mobilization, behaviour change and biological control in the prevention and control of dengue fever in Viet Nam. Dengue Bulletin, 2004, 28(Suppl.):57-61.

11. Chadee DD, Williams FLR, Kitron UD. Impact of vector control on a dengue fever outbreak in Trinidad, West Indies, in 1998. Tropical Medicine and International Health, 2005, 10:748-754.

12. Koh BKW et al. The 2005 dengue epidemic in Singapore: epidemiology, prevention and control. Annals of the Academy of Medicine, Singapore, 2008, 37:538-545.

13. Horstick $O$ et al. Dengue vector-control services: how do they work? A systematic literature review and country case studies. Transactions of the Royal Society of Tropical Medicine and Hygiene, 2010, 104(6):379-386.

14. Erlanger TE, Keiser J, Utzinger J. Effect of dengue vector control interventions on entomological parameters in developing countries: a systematic review and meta-analysis. Medical and Veterinary Entomology, 2008, 22:203-221.

15. Huang Y-M. The subgenus Stegomyioa of Aedes in the afrotropical region with keys to the species (Diptera: Culicidae). New Zealand, Magnolia Press, 2004:120. 